Electronic supplementary Information

\title{
Microwave Assisted Catalytic Degradation of Brilliant Green by Spinel Zinc Ferrite Sheets
}

\author{
Sandhya Mishra1, Tumesh Kumar Sahu², Priyanshu Verma1, Prashant Kumar ${ }^{2,3}$ *, Sujoy \\ Kumar Samanta ${ }^{1, *}$ \\ ${ }^{1}$ Department of Chemical and Biochemical Engineering, \\ ${ }^{2}$ Department of Physics, \\ 1,2Indian Institute of Technology Patna, Bihta, Patna, Bihar, India-801106. \\ ${ }^{3}$ Birck Nanotechnology Centre, Purdue University, West Lafayette, USA-47906.
}

Correspondence: Dr. Prashant Kumar: Phone, +91-612 302 8141, +91-9102830953, Email: prashantkumar@iitp.ac.in, magmemory@gmail.com, Dr. Sujoy Kumar Samanta: Phone: +91612302 8173,+91-9835355046, E-mail: sksamanta@iitp.ac.in.

Number of Pages: 8

Number of Figures: 6

Number of Tables: 1 
a

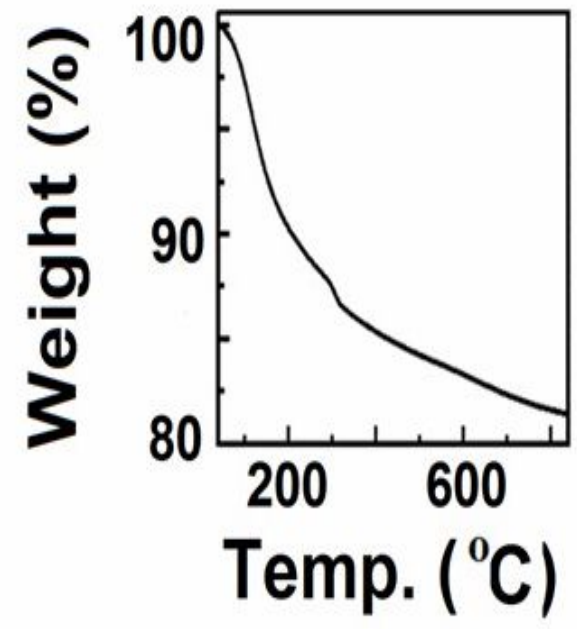

b

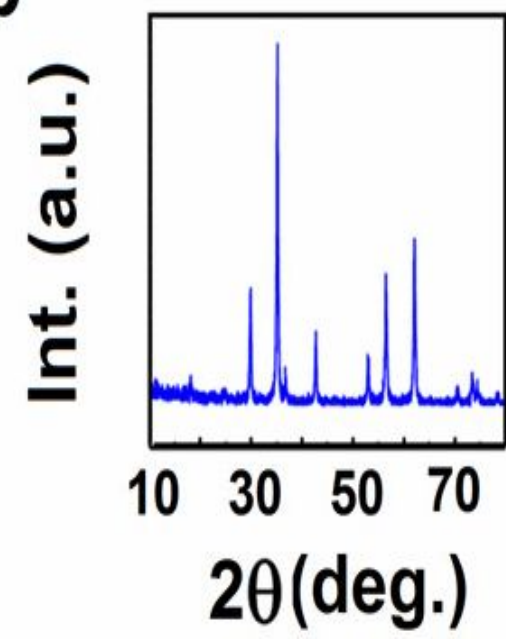

Figure S1 (a) Thermal Decomposition curve of $\mathrm{ZnFe}_{2} \mathrm{O}_{4}$, (b) XRD plot after MW Treatment. 


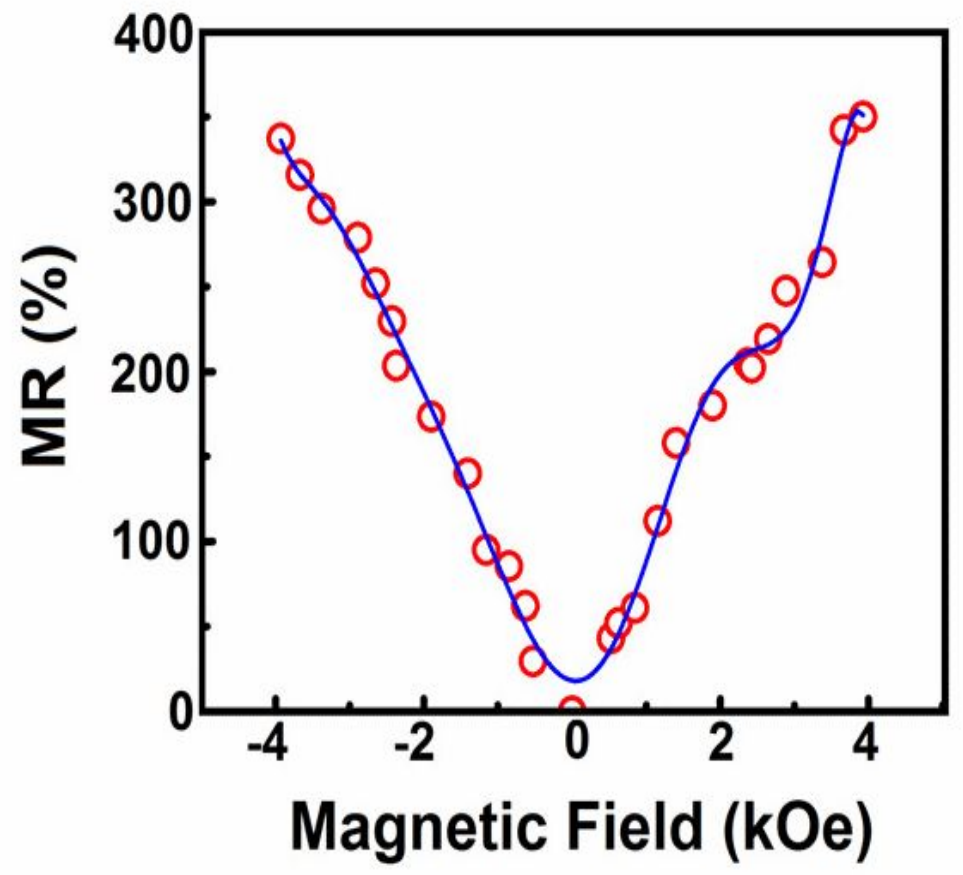

Figure S2 Magnetoresistance curve of $\mathrm{ZnFe}_{2} \mathrm{O}_{4}$. 

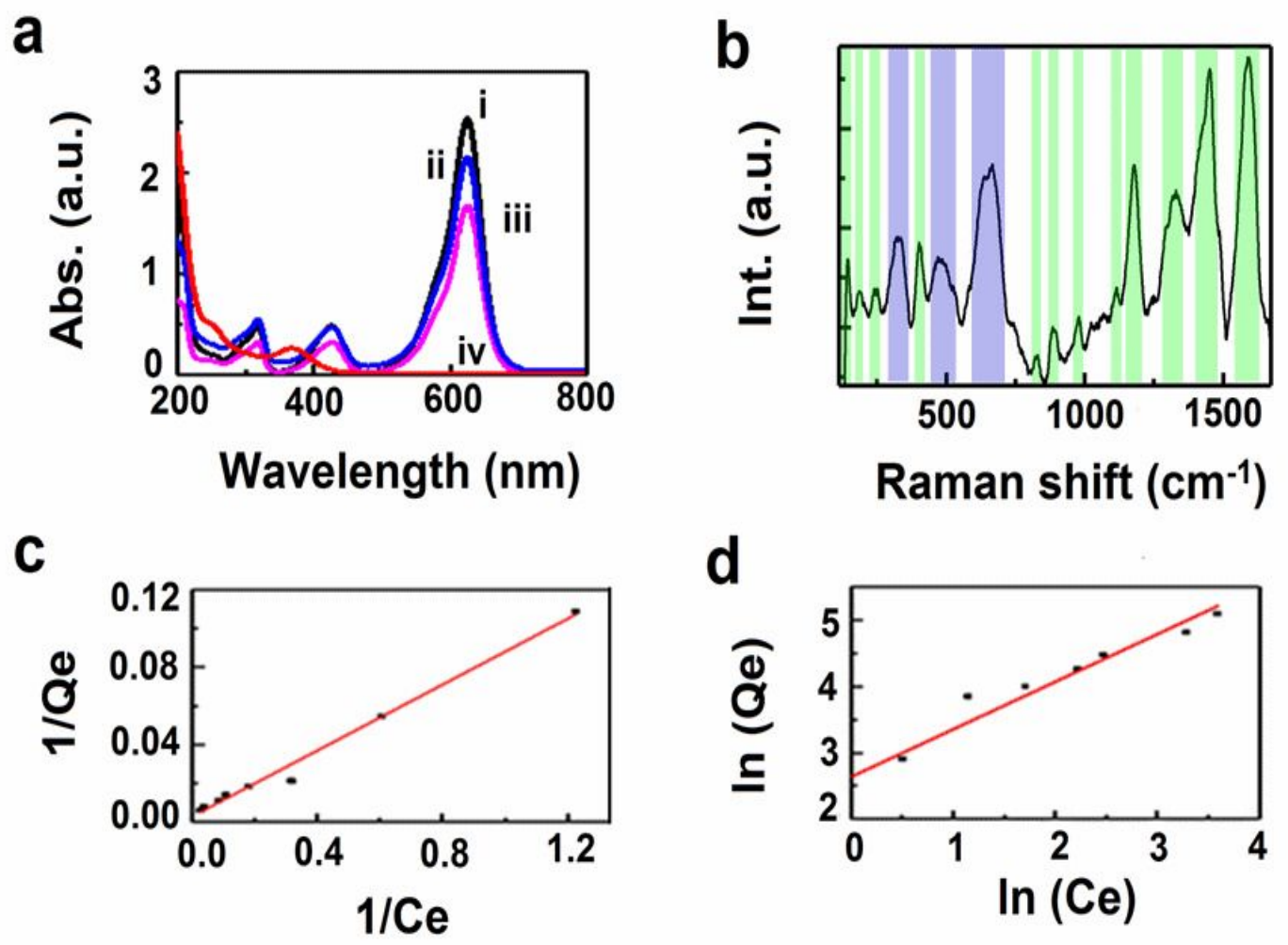

Figure S3 (a) UV-Vis absorption spectrogram of BG solution at different conditions (i) Original solution of BG (ii) MW irradiation for 5 min (iii) SZFO adsorption for 1 hour (iv) MW/SZFO for 5 min, (b) Raman spectra after adsorption, Adsorption Isotherm of BG onto MW catalyst $\mathrm{ZnFe}_{2} \mathrm{O}_{4}$ fitting with (c) Langmuir and (d) Freundlich model. 
Table S1 Adsorption isotherms of BG onto the MW catalyst SZFO fitting with (a) Langmuir Model; (b) Freundlich Model

\begin{tabular}{|c|c|c|c|c|c|c|}
\hline Adsorbate & \multicolumn{3}{|c|}{$\begin{array}{l}\text { Langmuir Model } \\
\frac{1}{Q_{e}}=\frac{1}{Q_{\max }}+\frac{1}{C_{e} Q_{\max } K_{L}}\end{array}$} & \multicolumn{3}{|c|}{$\begin{array}{l}\text { Freundlich Model } \\
\qquad Q_{e}=K_{F} C_{e}^{1 / n}\end{array}$} \\
\hline \multirow[t]{2}{*}{$(\mathrm{BG}) \mathrm{ZnFe}_{2} \mathrm{O}_{4}$} & $\mathbf{K}_{\mathrm{L}}$ & $\mathbf{q}_{\max }$ & $\mathbf{R}^{2}$ & $\mathbf{K}_{\mathrm{F}}$ & n & $\mathbf{R}^{2}$ \\
\hline & 0.032246 & 363.63 & 0.9898 & 13.873 & 1.39 & 0.9535 \\
\hline
\end{tabular}

Here, $\mathrm{K}_{\mathrm{L}}(\mathrm{l} / \mathrm{mg})$ and $\mathrm{q}_{\max }(\mathrm{mg} / \mathrm{g})$ are constants of the Langmuir Model and the maximum adsorption capacity of the adsorbent respectively. In addition, $\mathrm{K}_{\mathrm{F}}\left((\mathrm{mg} / \mathrm{g})(1 / \mathrm{mg})^{1 / \mathrm{n}}\right)$ and $\mathrm{n}$ are Freundlich constants. 
a

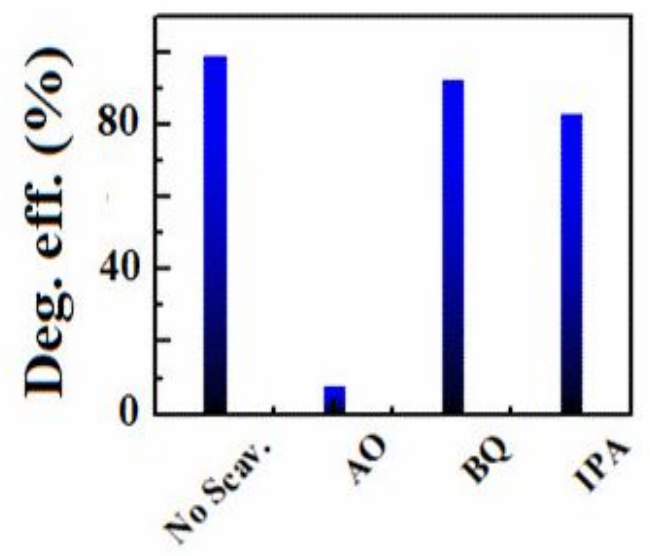

b

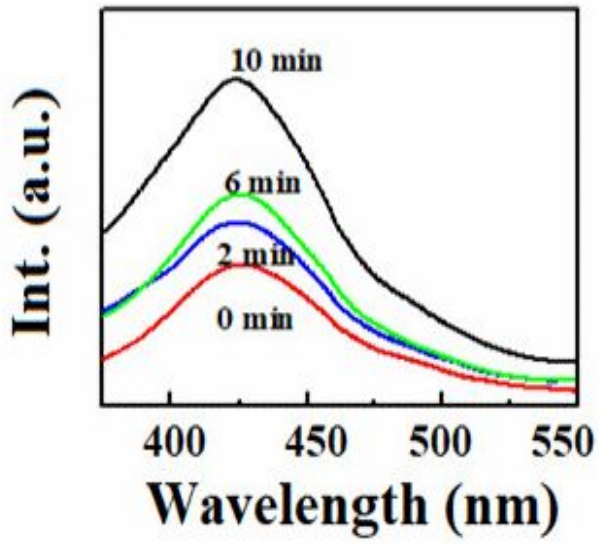

Figure S4 (a) Effects of a series of scavengers on the degradation efficiency of BG; (b) Fluorescence spectra of terephthalic acid $(0.3 \mathrm{mM}, 360 \mathrm{~W}$ MW power, $20 \mathrm{mg}$ ZFO) at different irradiation times. 

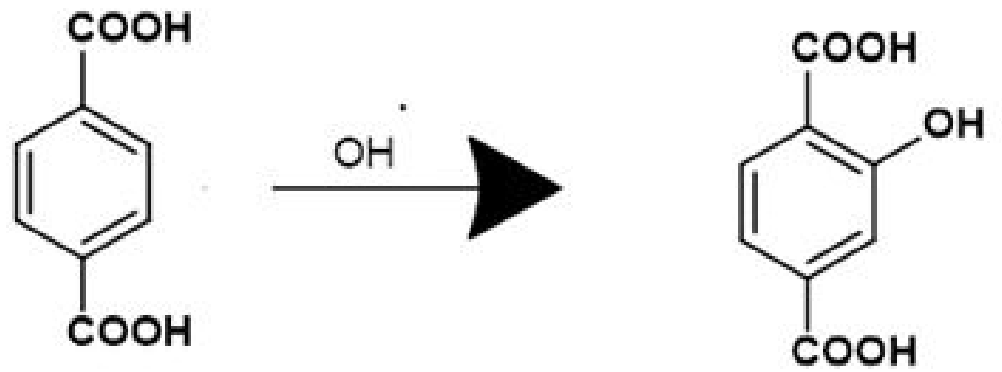

\section{terephthalic acid}

2-hydroxyterephthalic acid

Figure S5 Formation of luminescent 2-hydroxyterephthalic acid from terephthalic acid. 
- $\mathrm{ZnFe}_{2} \mathrm{O}_{4}$ Sheets

man Microwaves

1. Round Bottom Flask

2. Magnetron

3. Time control probe

4. Power control probe

5 . Display

6

6. Condenser unit

7. Connector

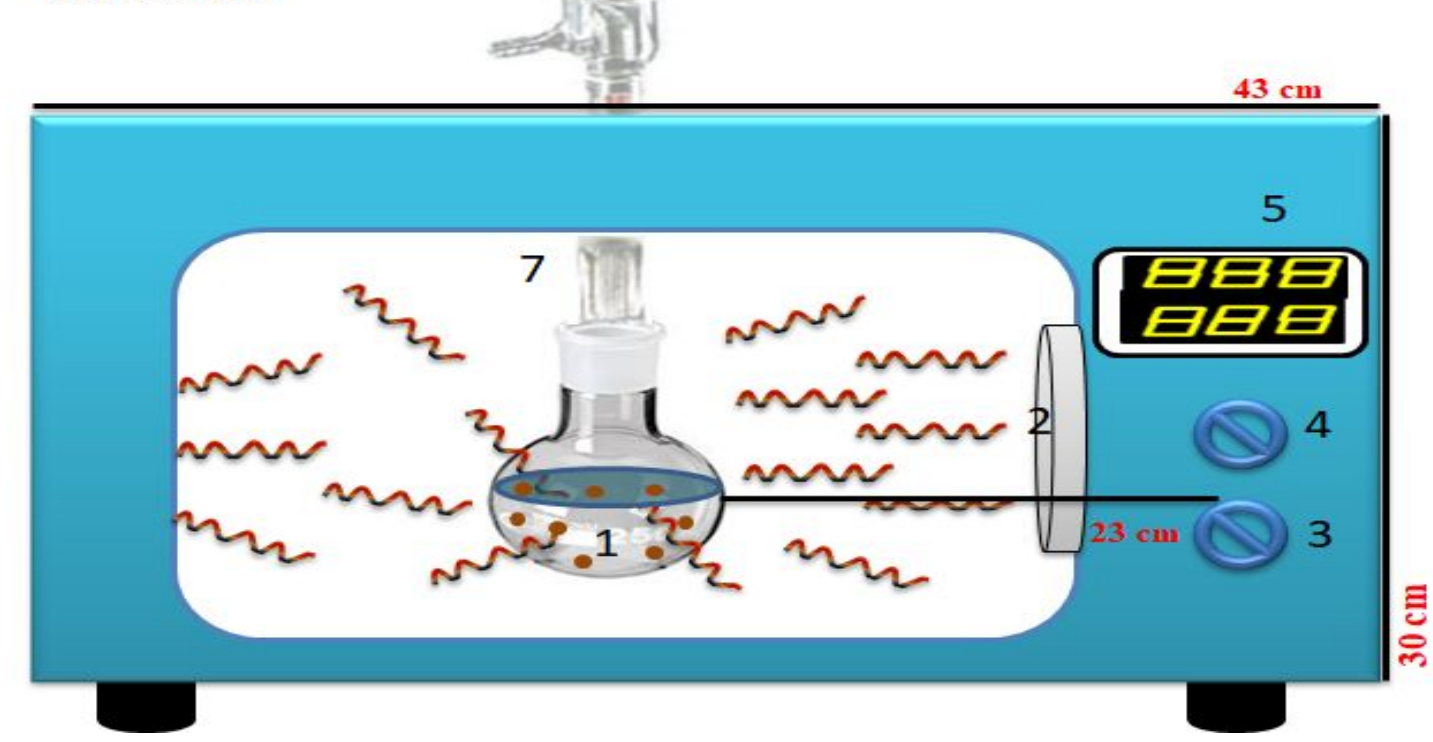

Figure S6 Schematic diagram for microwave irradiation with the condenser unit set up. 